\title{
Maternal factors pre- and during delivery contribute to gut microbiota shaping in newborns
}

\author{
Giuliano Rigon, Cristina Vallone, Valeria Lucantoni and Fabrizio Signore* \\ Department of Obstetrics and Gynaecology, S. Camillo-Forlanini Hospital, Rome, Italy \\ ${ }^{*}$ Correspondence: fsignore@scamilloforlanini.rm.it \\ Edited by: \\ Lorenza Putignani, Children's Hospital and Research Institute Bambino Gesù Hospital, Italy \\ Reviewed by: \\ Andrea Petrucca, Azienda Ospedaliera Sant' Andrea, Italy
}

Normally at birth, the human infant gut is sterile, but it becomes fully colonized within a few days with bacteria from the mother and the environment (Salminen and Isolauri, 2008).

An altered gut microbiota composition has been associated with attenuated immune responses to inflammation in experimental models and humans (Fanaro et al., 2003; Ly et al., 2011; Vebø et al., 2011).

The pioneer microbiota of the neonate may affect future actions of the immune system (Conroy and Walker, 2008; Karlsson et al., 2011; Vael et al., 2011).

The relation between the neonatal gut microbiota and the development of allergic diseases and obesity has led to several clinical trials of probiotics (live bacteria given orally that allow for intestinal colonization) in human subjects both during pregnancy or in the neonatal period. Probiotic trials thus far have failed to show a consistent preventive effect (Litonjua, 2012).

Many factors contribute to the shaping of this complex ecosystem, and all must be taken into account. Maternal gut microbiota is a factor in neonatal colonization. Reduced concentrations of Bifidobacterium and Bacteroides and increased numbers of Staphylococcus, Enterobacteriaceae were detected in overweight compared with normal-weight pregnant women (Santacruz et al., 2010).

Increased Enterobacteriaceae numbers were related to increased ferritin and reduced transferrin, while Bacteroides numbers were related to increased HDLcholesterol and folic acid levels (Santacruz et al., 2010; Table 1).

Population related factors are significant (Bäckhed, 2011). Karlsson et al. (2011) observed Lactobacillus in all neonates, other bacterial groups were detected only in
$14-30 \%$ of the subjects (Bifidobacterium, Enterococcus, and the Bacteroides fragilis group). Fallani compared neonatal fecal samples from Sweden, Scotland, Germany, Italy, and Spain. Bifidobacterium genus was predominant $(40 \%$ average proportion of total detectable bacteria), followed by Bacteroides (11.4\%) and Enterobacteria (7.5\%; Fallani et al., 2010). Differences in colonization pattern can be observed between infants in industrialized and developing countries (Adlerberth, 2008). Siblings increase the numbers of Bifidobacteria, while pets and country residence show no significance (Penders et al., 2006). Dominguez observed a neonatal colonization corresponding to maternal skin population in case of cesarean section and coincident with maternal vaginal flora in case of vaginal delivery (Dominguez-Bello et al., 2010).

Breastfeeding is a significant factor in the determination of neonatal gut microbiota. During lactation, cells from gut-associated lymphoid tissue travel to the breast via the lymphatics and peripheral blood (DonnetHughes et al., 2010).

Breast milk gives a flora rich in Bifidobacterium spp. Other obligate anaerobes, such as Clostridium spp. and Bacteroides spp., are more rarely isolated and also Enterobacteria and Enterococci are relatively few. Formula-fed babies are often colonized by other anaerobes in addition to Bifidobacteria and by facultatively anaerobic bacteria; the development of a "Bifidus flora” is unusual (Fanaro et al., 2003). Breastfeeding leads to higher Lactobacillus and lower count of E. coli, Clostridium difficile, B. fragilis (Penders et al., 2006; Fallani et al., 2010). After delivery, breastfeeding continues to enhance the original inoculum by specific lactic acid bacteria and
Bifidobacteria and bacteria from the mother's skin enabling the infant gut microbiota to be dominated by Bifidobacteria. Modifying this exposure can take place by probiotic bacteria when breastfeeding is not possible (Conroy and Walker, 2008; Salminen and Isolauri, 2008). Fecal Bifidobacterium and Lactobacillus/Enterococcus spp. counts were higher in breastfed than formula-fed infants at 6 months (Rinne et al., 2006; Table 1). Maternal and neonatal medical treatment is an issue. Newborns from mothers treated with antibiotics perinatally had lower proportions of Bacteroides and members of the Atopobium cluster. Antibiotics lower the count of Bifidobacteria and B. fragilis group, according to Penders et al. (2006). Gut microbiota is influenced by perinatal conditions. Ley et al. (2005) found that obese pregnant mice have a $50 \%$ reduction in Bacteroidetes and a proportional increase in Firmicutes compared to normal controls on the same diet. One mechanism here could lie in the ability of specific gut microbes to induce excessive energy harvests (Collado et al., 2008). Overweight women show increases of Clostridium, Bacteroides, Staphylococcus, and Akkermansia during pregnancy according to the author. Their infants' fecal microbial composition was related to the weight and weight gain of their mothers during pregnancy (Collado et al., 2010; Table 1).

In extremely low-birth-weight infants characterized by antibiotic therapy, parenteral nutrition, delayed oral feedings, and intubation the gut is colonized by a small number of bacterial species; Lactobacillus and Bifidobacterium spp. are seldom identified (Fanaro et al., 2003). Rougé et al. (2010) indicated that the gastrointestinal tract of preterm infants, born less than 33 weeks, has a low biodiversity. According to Dai and 
Table 1 | Effects of neonatal physiological and pathological conditions on gut microbiota onset and distribution.

\begin{tabular}{|c|c|c|c|c|c|}
\hline Escherichia coli & +++ & & $\begin{array}{l}\text { Increased ferritin/reduced } \\
\text { transferrin }\end{array}$ & & Santacruz et al. (2010) \\
\hline Bacteroides spp. & H+ & & $\begin{array}{l}\text { Increased HDL- } \\
\text { cholesterol/folic acid }\end{array}$ & & Santacruz et al. (2010) \\
\hline $\begin{array}{l}\text { Bifidobacterium spp., } \\
\text { Bacteroides spp. }\end{array}$ & & ++ & & $\begin{array}{l}\text { Overweight pregnant } \\
\text { women }\end{array}$ & Santacruz et al. (2010) \\
\hline $\begin{array}{l}\text { Bifidobacterium spp., } \\
\text { Lactobacillus spp. }\end{array}$ & ++ & & Baby breast feeding & & $\begin{array}{l}\text { Fanaro et al. (2003), Rinne } \\
\text { et al. (2006) }\end{array}$ \\
\hline Bacteroides spp. & & $+H$ & & Mouse obesity & Ley et al. (2005) \\
\hline Firmicutes & $+1+$ & & & Mouse obesity & Ley et al. (2005) \\
\hline $\begin{array}{l}\text { Clostridium spp., Bacteroides } \\
\text { spp., Staphylococcus spp., } \\
\text { Akkermansia spp. }\end{array}$ & $+H$ & & & $\begin{array}{l}\text { Overweight pregnant } \\
\text { women }\end{array}$ & Collado et al. (2010) \\
\hline $\begin{array}{l}\text { Lactobacillus spp., } \\
\text { Bifidobacterium spp. }\end{array}$ & & +1 & & $\begin{array}{l}\text { Extremely low-birth- } \\
\text { weight infants }\end{array}$ & $\begin{array}{l}\text { Fanaro et al. (2003), } \\
\text { Rougé et al. (2010), Dai } \\
\text { and Walker (1999) }\end{array}$ \\
\hline Clostridium spp., Bacillus spp. & $+H$ & & Vaginal delivery & & $\begin{array}{l}\text { Penders et al. (2006), Lif } \\
\text { Holgerson et al. (2011), } \\
\text { Huurre et al. (2008) }\end{array}$ \\
\hline $\begin{array}{l}\text { Lactobacillus spp., Enterococcus } \\
\text { spp., Clostridium spp. }\end{array}$ & & H & $\begin{array}{l}\text { Probiotic administration } \\
\text { during pregnancy }\end{array}$ & & Rinne et al. (2006) \\
\hline
\end{tabular}

Walker (1999), premature infants requiring intensive care acquire intestinal organisms slowly, and the establishment of bifidobacterial flora is retarded. The aberrant colonization of the premature infant may contribute to the development of necrotizing enterocolitis.

Neonatal gut is related to mode of delivery. In infants born by cesarean section (C-section) the establishment of a stable flora is delayed (Fanaro et al., 2003). Significantly more bacterial taxa were detected in the infants delivered vaginally (79 species/species clusters) compared with infants delivered by C-section (54 species/species clusters; Lif Holgerson et al., 2011). Newborns delivered by C-section had lower proportions of Bacteroides and members of the Atopobium cluster (Fallani et al., 2010). Infants delivered by C-section had fewer bifidobacteria at an early age and were shown to mount a stronger humoral immune response (Huurre et al., 2008). At 1 month of age, the total gut bacterial cell counts per $1 \mathrm{~g}$ feces were higher in vaginally delivered infants. This distinction was mainly due to the greater number of Bifidobacteria in vaginally delivered infants. During the first year of life, the total number of immunoglobulin (Ig) A, IgG-, and IgMsecreting cells was lower in infants born by vaginal delivery than in those born by C-section, possibly reflecting different antigen exposure (Huurre et al., 2008).
Dominguez observed a neonatal colonization corresponding to maternal skin population in case of c-section and coincident with maternal vaginal flora in case of vaginal delivery (Dominguez-Bello et al., 2010). An extensive Netherlands study shows conclusively that vaginal delivery brings on a faster colonization by all species, mostly Bifidobacteria, with high B. fragilis and low C. difficile counts (Table 1). High Clostridium counts were associated with clinical complications and hospital admittance (Penders et al., 2006). Most significantly things change with age. The bacterial flora is usually heterogeneous during the first days of life, independently of feeding habits. After the first week of life, a stable bacterial flora is usually established (Fanaro et al., 2003). 
The first bacteria to establish in the neonatal gut are usually aerobic or facultative anaerobic bacteria, like Enterobacteria, Enterococci, and Staphylococci. During their growth, they consume oxygen and change the intestinal milieu making it suitable for the proliferation of anaerobic bacteria. Bifidobacterium, Clostridium, and Bacteroides are among the first anaerobes establishing in the microbiota. As more oxygen-sensitive species establish and the complexity of the microbiota increases, the population sizes of aerobic and facultative bacteria decline (Adlerberth, 2008).

Vebo showed a decrease in Staphylococci from 10 days to 4 months and a peak of Bifidobacteria and Bacteroides at 4 months (Gueimonde et al., 2006; Vebø et al., 2011). Clinical effects of an altered neonatal colonization have been noticed. In the past 20-30 years, the prevalence of atopic diseases, particularly among children in the Western world, has increased. It has been suggested that Western lifestyle may have reduced the overall exposure to microbial stimulation early in life (Øien et al., 2006).

The pioneer microbiota of the neonate may affect future actions of the immune system (Karlsson et al., 2011). A close relationship between allergic sensitization and the development of the intestinal microflora may occur in infancy. Intestinal microorganisms could down-regulate the allergic inflammation by counterbalancing type 2 T-helper cell responses and by enhancing antigen exclusion through an immunoglobulin Ig-A response (Kirjavainen and Gibson, 1999). According to Vael et al. (2011), early colonization by Clostridium coccoides or $B$. fragilis could lead to asthma in later life.

Altered gut colonization could lead to obesity in later life. Germ-free mice are protected against developing diet-induced obesity. The gut microbiota affects expression of secreted proteins in the gut, which modulate lipid metabolism in peripheral organs and is a source of pro-inflammatory molecules that augment adipose inflammation and macrophage recruitment by signaling through the innate immune system (Bäckhed, 2011). An intriguing observation is that neonates treated with antibiotics during the first 6 months of life had an increased risk of overweight among children of normal-weight mothers (OR: 1.54, 95\% CI: 1.09-2.17) with a decreased risk of overweight among children of over- weight mothers (Ajslev et al., 2011). Trials with probiotic precursors administered to the mother have been reported. Maternal administration of Lactobacillus rhamnosus GG (L-GG, ATCC 53103) during late pregnancy promotes a Bifidobacteria profile of infant gut microbiota, similar to that of a healthy breastfed infant. Microbial diversity in neonatal gut microbiota was not influenced by this probiotic administration at 1 week postpartum (Ismail et al., 2012). In a prospective randomized study Gueimonde et al. (2006) showed that maternal L. rhamnosus administration during late pregnancy is associated in the neonates at 5 days of age with a higher occurrence of Bifidobacterium brevis and lower of Bifidobacterium adolescentis. Probiotic supplementation has been tried in newborns. One-hundred thirty-two neonates were randomized in a placebo group and the others were treated with L. rhamnosus. For 6 months after delivery, mothers had been treated prenatally for 6 months in the treatment group. At 6 months, there were less Clostridia in feces in the placebo compared with the probiotic group $(P=0.026)$, whereas after longterm follow-up at 2 years, there were less Lactobacilli/Enterococci and Clostridia in feces in the probiotic group than in the placebo group (Rinne et al., 2006; Table 1).

Rinne showed in another randomized trial of neonatal L. rhamnosus administration that at 3 months IgG-secreting cells in breastfed infants supplemented with probiotics was higher (Rinne et al., 2005). Chierici underlined the importance of a probiotic diet with bifidogenic activity of non-digestible but fermentable carbohydrates (Chierici et al., 2003).

In conclusion, we infer that many observations indicate the significance of bacterial neonatal colonization of the gut. A tighter control of factors influencing this phenomenon is warranted if results of preventive or therapeutic measures, or effects of maternal, or perinatal conditions is to be identified.

\section{ACKNOWLEDGMENT}

Grant of "Fondazione Enrico ed Enrica Sovena" to Cristina Vallone.

\section{REFERENCES}

Adlerberth, I. (2008). Factors influencing the establishment of the intestinal microbiota in infancy. Nestle Nutr. Workshop Ser. Pediatr. Program. 62, 13-29; discussion 29-33.
Ajslev, T. A., Andersen, C. S., Gamborg, M., Sørensen, T. I., and Jess, T. (2011). Childhood overweight after establishment of the gut microbiota: the role of delivery mode, pre-pregnancy weight and early administration of antibiotics. Int. J. Obes. (Lond.) 35, 522-529.

Bäckhed, F. (2011). Programming of host metabolism by the gut microbiota. Ann. Nutr. Metab. 58, 44-52.

Chierici, R., Fanaro, S., Saccomandi, D., and Vigi, V. (2003). Advances in the modulation of the microbial ecology of the gut in early infancy. Acta Paediatr. 91, 56-63.

Collado, M. C., Isolauri, E., Laitinen, K., and Salminen, S. (2008). Distinct composition of gut microbiota during pregnancy in overweight and normal-weight women. Am. J. Clin. Nutr. 88, 894-899.

Collado, M. C., Isolauri, E., Laitinen, K., and Salminen, S. (2010). Effect of mother's weight on infant's microbiota acquisition, composition, and activity during early infancy: a prospective follow-up study initiated in early pregnancy. Am. J. Clin. Nutr. 92, 1023-1030.

Conroy, M. E., and Walker, W. A. (2008). Intestinal immune health. Nestle Nutr. Workshop Ser. Pediatr. Program. 62, 111-121; discussion 121-125.

Dai, D., and Walker, W. A. (1999). Protective nutrients and bacterial colonization in the immature human gut. Adv. Pediatr. 46, 353-382.

Dominguez-Bello, M. G., Costello, E. K., Contreras, M., Magris, M., Hidalgo, G., Fierer, N., and Knight, R. (2010). Delivery mode shapes the acquisition and structure of the initial microbiota across multiple body habitats in newborns. Proc. Natl. Acad. Sci. U.S.A. 107, 11971-11975.

Donnet-Hughes, A., Perez, P. F., Doré, J., Leclerc, M., Levenez, F., Benyacoub, J., Serrant, P., Segura-Roggero, I., and Schiffrin, E. J. (2010). Potential role of the intestinal microbiota of the mother in neonatal immune education. Proc. Nutr. Soc. 69, 407-415.

Fallani, M., Young, D., Scott, J., Norin, E., Amarri, S., Adam, R., Aguilera, M., Khanna, S., Gil, A., Edwards, C. A., Doré, J., and Other Members of the INFABIO Team. (2010). Intestinal microbiota of 6-week-old infants across Europe: geographic influence beyond delivery mode, breast-feeding, and antibiotics. $J$. Pediatr. Gastroenterol. Nutr. 51, 77-84.

Fanaro, S., Chierici, R., Guerrini, P., and Vigi, V. (2003). Intestinal microflora in early infancy: composition and development. Acta Paediatr. 91, 48-55.

Gueimonde, M., Sakata, S., Kalliomäki, M., Isolauri, E., Benno, Y., and Salminen, S. (2006). Effect of maternal consumption of lactobacillus GG on transfer and establishment of fecal bifidobacterial microbiota in neonates. J. Pediatr. Gastroenterol. Nutr. 42, 166-170.

Huurre, A., Kalliomäki, M., Rautava, S., Rinne, M., Salminen, S., and Isolauri, E. (2008). Mode of delivery - effects on gut microbiota and humoral immunity. Neonatology 93, 236-240.

Ismail, I. H., Oppedisano, F., Joseph, S. J., Boyle, R. J., Robins-Browne, R. M., and Tang, M. L. (2012). Prenatal administration of Lactobacillus rhamnosus has no effect on the diversity of the early infant gut microbiota. Pediatr. Allergy Immunol. 23, 255-258.

Karlsson, C. L., Molin, G., Cilio, C. M., and Ahrné, S. (2011). The pioneer gut microbiota in human neonates vaginally born at term-a pilot study. Pediatr. Res. 70, 282-286.

Kirjavainen, P. V., and Gibson, G. R. (1999). Healthy gut microflora and allergy: factors influencing development of the microbiota. Ann. Med. 31, 288-292. 
Ley, R. E., Bäckhed, F., Turnbaugh, P., Lozupone, C. A., Knight, R. D., and Gordon, J. I. (2005). Obesity alters gut microbial ecology. Proc. Natl. Acad. Sci. U.S.A. 102, 11070-11075.

Lif Holgerson, P., Harnevik, L., Hernell, O., Tanner, A. C., and Johansson, I. (2011). Mode of birth delivery affects oral microbiota in infants. J. Dent. Res. 90, 1183-1188.

Litonjua, A. A. (2012). Fat-soluble vitamins and atopic disease: what is the evidence? Proc. Nutr. Soc. 71, 67-74.

Ly, N. P., Litonjua, A., Gold, D. R., and Celedón, J. C. (2011). Gut microbiota, probiotics, and vitamin D: interrelated exposures influencing allergy, asthma, and obesity? J. Allergy Clin. Immunol. 127, 1087-1094; quiz 1095-1096.

Øien, T., Storrø, O., and Johnsen, R. (2006). Intestinal microbiota and its effect on the immune system a nested case-cohort study on prevention of atopy among small children in Trondheim: the IMPACT study. Contemp. Clin. Trials 27, 389-395.

Penders, J., Thijs, C., Vink, C., Stelma, F. F., Snijders, B., Kummeling, I., van den Brandt, P.A., and Stobberingh, E. E. (2006). Factors influencing the composition of the intestinal microbiota in early infancy. Pediatrics $118,511-521$.
Rinne, M., Kalliomaki, M., Arvilommi, H., Salminen, S., and Isolauri, E. (2005). Effect of probiotics and breastfeeding on the bifidobacterium and lactobacillus/enterococcus microbiota and humoral immune responses. J. Pediatr. 147, 186-191.

Rinne, M., Kalliomäki, M., Salminen, S., and Isolauri, E. (2006). Probiotic intervention in the first months of life: short-term effects on gastrointestinal symptoms and long-term effects on gut microbiota. J. Pediatr. Gastroenterol. Nutr. 43, 200-205.

Rougé, C., Goldenberg, O., Ferraris, L., Berger, B., Rochat, F., Legrand, A., Göbel, U. B., Vodovar, M., Voyer, M., Rozé, J. C., Darmaun, D., Piloquet, H., Butel, M. J., and de La Cochetière, M. F. (2010). Investigation of the intestinal microbiota in preterm infants using different methods. Anaerobe 16, 362-370.

Salminen, S., and Isolauri, E. (2008). Opportunities for improving the health and nutrition of the human infant by probiotics. Nestle Nutr. Workshop Ser. Pediatr. Program. 62, 223-233; discussion 233-237.

Santacruz, A., Collado, M. C., García-Valdés, L., Segura, M. T., Martín-Lagos, J. A., Anjos, T., Martí-Romero, M., Lopez, R. M., Florido, J., Campoy, C., and Sanz, Y. (2010). Gut microbiota composition is associated with body weight, weight gain and biochemical parameters in pregnant women. Br. J. Nutr. 104, 83-92.

Vael, C., Vanheirstraeten, L., Desager, K. N., and Goossens, H. (2011). Denaturing gradient gel electrophoresis of neonatal intestinal microbiota in relation to the development of asthma. BMC Microbiol. 11, 68. doi: 10.1186/1471-2180-11-68

Vebø, H. C., Sekelja, M., Nestestog, R., Storrø, O., Johnsen, R., Øien, T., and Rudi, K. (2011). Temporal development of the infant gut microbiota in immunoglobulin E-sensitized and nonsensitized children determined by the GA-map infant array. Clin. Vaccine Immunol. 18, 1326-1335.

Received: 21 March 2012; accepted: 19June 2012; published online: 05 July 2012.

Citation: Rigon G, Vallone C, Lucantoni V and Signore F (2012) Maternal factors pre-and during delivery contribute to gut microbiota shaping in newborns. Front. Cell. Inf. Microbio. 2:93. doi: 10.3389/fcimb.2012.00093

Copyright (c) 2012 Rigon, Vallone, Lucantoni and Signore. This is an open-access article distributed under the terms of the Creative Commons Attribution License, which permits use, distribution and reproduction in other forums, provided the original authors and source are credited and subject to any copyright notices concerning any third-party graphics etc. 